\title{
Training parents of children with autism to implement the picture exchange communication intervention
}

\author{
Batool T. Alsayedhassan ${ }^{1}$, Devender R. Banda ${ }^{2}$ Nora Griffin-Shirley ${ }^{2}$ \\ ${ }^{1}$ Case Management Supervisor \& ABA Consultant, Gulf Medical Centers Developmental Disabilities and Autism Unit, Dammam, Saudi Arabia; \\ ${ }^{2}$ Department of Educational Psychology \& Leadership Texas Tech University, Lubbock, TX, USA
}

Purpose: We investigated the effects of behavioral skills training package with parents to use picture exchange communication system (PECS) with their children with autism spectrum disorder (ASD) to develop communication skills.

Methods: Two parents and their children with ASD (one child per family) participated in this study. A multiple baseline design was used during the parents' training, and a changing criterion design was used during parents' implementation of PECS with children.

Results: Results indicated that both parents implemented PECS intervention with their children with high procedural integrity and required minimal feedback through Bug-in-Ear at the end of the intervention. Moreover, both children acquired independent picture exchanges with their parents who implemented PECS training and generalized and maintained the skills.

Conclusions: The findings suggest that when parents receive appropriate training and feedback, they can train their children to use PECS to independently request desired items or activities. The current study extends existing research on PECS by teaching parents as the primary PECS trainers to implement the strategy with their children.

Keywords: Picture Exchange Communication System (PECS), Autism Spectrum Disorders (ASD), Parent training, Communication, Requesting skills, Bug-in-Ear (BIE)

\section{INTRODUCTION}

Autism spectrum disorder (ASD) is a developmental disorder characterized by difficulties in social-communication and behaviors. In the area of social-communication, individuals with ASD usually engage in prelinguistic behaviors to gain access by reaching, pointing, and guiding a communication partner's hands to a desired object [1]. Such forms of communication modalities are problematic to both children with ASD and to their communication partners because some of these interactions are difficult to understand and interpret [2]. These impairments need to be addressed using effective strategies to promote communication and appropriate social skills.

A variety of interventions are available to support social-communication skills for children with ASD to enhance their communication at home, school, and in the community. These interventions include discrete trial instruction [3], verbal behaviors that includes echoes, mands, tacts, and intraverbals [4], pivotal response training [5], video

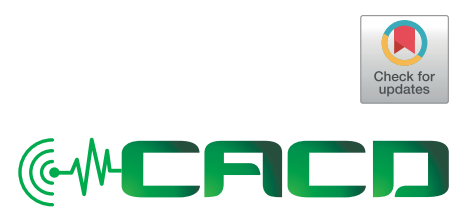

Received: December 28, 2019

Revision: April 27, 2020

Accepted: April 27, 2020

Correspondence:

Devender R. Banda

Department of Educational Psychology and Leadership, College of Education, P0 Box 41071, Texas Tech University, Lubbock, TX 79409, USA

Tel: +8068344827

Fax: +806-742-2179

E-mail: devender.banda@ttu.edu

(C) 2020 The Korean Association of SpeechLanguage Pathologists

This is an Open Access article distributed under the terms of the Creative Commons Attribution NonCommercial License (https://creativecommons.org/ licenses/by-nc/4.0/) which permits unrestricted noncommercial use, distribution, and reproduction in any medium, provided the original work is properly cited. 
modeling and self-modeling [6], and augmentative and alternative communication (AAC) interventions [7]. The AAC system consists of unaided interventions that do not require any external equipment besides parts of the body (i.e., sign language, gestures, manual signs) and aided interventions that require external aids such as picture-based methods and electronic devices [7].

A commonly used AAC intervention is picture exchange communication system (PECS) [8]. Researchers have used PECS to teach the communication skills that included requesting and commenting by exchanging picture cards with communication partners [8]. The range of PECS treatment effectiveness is estimated from $50-90 \%$ depending on the type of outcomes measured [9].

According to Bondy and Frost [10], the PECS training protocol involves six Phases (I-VI). Phase I teaches individuals with communication difficulties to request items using a picture card. Phase II instructs children how to request desired items by traveling to a communication book and to the communication partner. Phase III is intended to instruct picture discrimination between two or more pictures from a communication book. Phase IV teaches the child to develop a sentence by combining pictures (e.g., "I want"+ "desired item"). In Phase V, children are taught how to respond to questions (e.g., '"What do you want?"). During Phase VI, additional sentence starters through the use of pictures are introduced to the student (e.g., "I see," "I hear," and "I smell").

PECS research shows that a majority of studies were conducted by researchers rather than parents. Recently, Alsayedhassan, Banda and Griffin-Shirley [11] reviewed 13 studies to evaluate the mastery of PECS training by parents and practitioners, and to examine PECS effects on communication skills in children with ASD. Results indicated that parents and practitioners were able to implement PECS with high procedural integrity. Additionally, PECS was effective in developing communication skills for individuals with ASD. However, only 5 of 13 studies were conducted by training parents to implement PECS with their children with autism and other developmental disabilities [12-16]. Results of these five studies indicated that children with autism improved their communication skills. Consequently, the investigators concluded that more research is needed concerning the efficacy of parent training on PECS and its impact on improving communication skills in children with ASD. Parental involvement to implement interventions is widely known to be an effective factor for the child's development and is considered the best practice for young children with ASD. Several strategies have been used to train parents and professionals to implement communication interventions such as Behavioral Skills Training (BST).

Researchers have used the BST package which includes written instructions, modeling, watching videos, practice, and feedback $[13,15]$. Verbal feedback is an essential part of this training program, which includes error correction, reinforcement, and answering questions before, during, or after the intervention sessions. In several PECS studies, researchers provided feedback directly by discussing with practitioners or parents during practice sessions [17-19]. Another method that could provide immediate feedback during PECS implementation is the Bug-in-Ear (BIE).

The BIE is a communication device that is small, wireless, and easy to use. This device can assist in providing one- or two-way audio communication between the investigator and teacher/parent during training. Immediate feedback is more likely to assist a trainee to acquire the skills faster and use them more frequently than delayed feedback [20]. Studies have been conducted using a BIE device to provide immediate feedback during teacher training to implement interventions with students with disabilities [21,22]. No studies have reported the amount or frequency of feedback messages parents needed during PECS implementation with their children with autism.

Therefore, this study focused on the following questions: 1) Do parents acquire mastery of PECS stages after BST training?; 2) Do children with autism acquire, maintain, and generalize communication skills by using PECS with their parents?; 3) How many feedback messages do parents require during PECS stages?; and 4) What is the perception of parents regarding PECS?

\section{METHODS}

\section{Participants}

The university's Human Research Protection Program approved the study. Two parents and their two sons with ASD were recruited for the study. The following inclusion criteria were used: (a) the participating parents had a child diagnosed with ASD; (b) the parents were the caregiver for their child; (c) the parents had no previous history of using PECS with their child; (d) the child with ASD was between 3 and 12 years and was non-verbal or used very limited expressive language; (e) the child with ASD had no history of using PECS; and (f) the child had hearing and vision within normal range. 


\section{Ray}

Ray was three years old with a diagnosis of autism. He was verbally limited and could only say some numbers (e.g., 3, 8, 10) and his speech was unintelligible. Per the Autism Diagnostic Observation Schedule-Second Edition (ADOS-2) [23], Ray demonstrated very few communication skills, but he could randomly count numbers. Results of the Vineland Adaptive Behavior Scales-Second Edition (VABS-2) [24] indicated that Ray's functional skills (communication, daily living, socialization, and adaptive behavior) composite was in the moderately low to low range. In addition, the results of the Stanford-Binet Intelligence Scales-Fifth Edition (SB-V) [25] demonstrated that the standard score for Ray's full-scale IQ was 64 (extremely low range), and his nonverbal IQ was 75 (below average), while his verbal IQ was 56 (extremely low range) indicating a significant difficulty in understanding spoken language. Ray's mother reported that he was taught sign language to communicate and did not have any experience using PECS.

\section{Ray's mother}

Ray's mother was a 35-year-old with two children. She had a bachelor's degree in education and was employed full-time as a teacher.

\section{Jack}

Jack was eight years old and was diagnosed with autism by a pediatrician at the age of three years. He was enrolled in a special education program located in an elementary school, where he received speech therapy, occupational therapy, and behavior intervention to reduce his aggressive behavior. Jack was assessed using the Gilliam Autism Rating Scale-Second Edition (GARS-2) [26] to evaluate his functional and language skills. The results showed standard scores of 47, 64, 61, and 72 on communication, daily living skills, socialization skills, and motor skills respectively, with a composite score of 58 . At the beginning of the study, Jack had limited verbal expressions (a few words) and was otherwise noncommunicative. Also, Jack exhibited aggressive behaviors including hitting, kicking, spitting, scratching, and throwing items toward others. Further information provided by Jack's father prior to participation in this study showed that Jack primarily communicated his needs and wants through idiosyncratic means such as physically moving to a desired item or pulling an adult towards the item. In addition, Jack had a difficult time working with different therapists. Jack received sign language training but did not use it frequently.

\section{Jack's father}

Jack's father was a 31-year-old with one child. He was in the first year of graduate school and worked part-time.

\section{Settings}

The study took place in a therapy room in a university setting, and at the participants' homes. The training sessions were conducted in a therapy room at a university that was equipped with a one-way mirror to allow the investigator to provide immediate feedback to parents. The generalization and followup probes were conducted at the participants' homes.

\section{Materials}

Materials included a communication book for PECS, a threering binder, several strips of Velcro, and several 2-by-2 inch laminated photographs that matched the preferred items used in the study. Other materials utilized included data collection sheets, a timer, a pen/marker for marking correct or incorrect responses, and a camera to record sessions. Additionally, the investigator used a Tronfy Minutesi4 Bug-in-Ear ${ }^{\circledR}$ to provide feedback to the parents when they implemented PECS with their children. In addition, a collection of preferred snacks and toys were provided that were identified through a preference assessment.

\section{Trainers}

The primary trainer was the first author of the study and a doctoral student. Additionally, another graduate student participated in training parents. Parents received formal training in PECS by the trainers, and when parents mastered the criteria for each phase of PECS, they implemented the PECS phase with their children in the therapy room.

\section{Dependent variables \\ Parents}

The primary dependent variable was the percent correct of PECS implementation in Phases I, II, and III. The correct implementation was defined when parents implemented a PECS step in each phase accurately as defined in the PECS procedure. The incorrect response was coded when parents missed a step of PECS phase or when they did not follow the sequence of the steps in each phase. Additionally, when parents implemented PECS with their children, the percent of correct implementation of steps in each phase were tracked. The mastery criterion was $100 \%$ for each phase with two consecutive sessions. The percentage for each session was calculated 
using the number of correct responses divided by the total number of exchanges during the sessions multiplied by 100 .

\section{Children}

The percent of correct exchanges of pictures using PECS to request the preferred items were measured. The independent responses were coded when the child picked up the picture from the communication book and exchanged the picture with the communication partner to receive the desired item within $5 \mathrm{~s}$ after presentation of the item without a prompt. The incorrect response was defined when the child reached to the preferred item without using a picture. The mastery criterion was $80 \%$ for each phase with unprompted picture exchanges for a minimum of two consecutive sessions. The percentage for each session was calculated using the number of correct responses divided by the total number of exchanges during the session multiplied by 100 .

\section{Independent variable}

The independent variable was the PECS training from Phase I through IIIB using the BST package (i.e., written and verbal instructions, modeling, role play, feedback). More details of the BST package training are provided in later part of this article. The PECS Phases were taught to the parents, and then parents implemented PECS with their children. Each Phase was taught separately to parents until they mastered the criterion ( $100 \%$ with two consecutive sessions). Then, parents implemented the learned PECS Phase with their children until their children mastered the criterion with $80 \%$ accuracy. When the children mastered the criterion, parents received training for the next Phase, and so on.

\section{Experimental designs Parents}

A multiple-baseline design across participants was used for parents training to evaluate the impact of the intervention. The baseline sessions began concurrently across both parents until demonstrating stable data. The treatment was introduced systematically for one parent, and the baseline data collection continued with the other parent [27]. When the first parent mastered a PECS phase, the intervention was introduced to the second parent.

\section{Children with ASD}

A changing-criterion design [27] was implemented with children to evaluate the effects of parent-implemented PECS training. The reason for selecting this design was to teach requesting skills using PECS independently in a stepwise manner. The procedure of changing-criteria design began with an initial baseline phase and then parents moved to the treatment phase. The criterion was consistent at $80 \%$ with two consecutive sessions within each phase. However, in each phase the participants were expected to demonstrate more complex skills prior to advancing to another phase. Through this design provides a weak functional relation in the current study, it was adopted from another similar PECS study [28].

\section{OVERVIEW OF THE PROCEDURE}

\section{Preference assessment}

An indirect preference assessment was conducted through interviewing parents about their children's preferred items. The parents were given a checklist to indicate which items were most preferred. The investigator then conducted a direct assessment with their child to verify the preferred items that were identified by parents. A Multiple-Stimulus without Replacement Preference Assessment (MSWO) [29] was conducted by presenting seven to nine preferred items representing a combination of food, toys, and activities. During the sessions when the child reached for an item, the investigator provided the child with a small piece of an edible item or $30 \mathrm{~s}$ of play when toy was selected. After selecting an item, the investigator removed the selected item and presented the remaining items in the next trial. The session continued until all items had been selected by the child. Each session included seven to nine trials and lasted about 10-12 minutes. In addition, brief preference assessments were conducted prior to each session throughout the day by asking the child to choose one item between several preferred items to reduce satiation.

\section{Baseline}

The baseline sessions were conducted in two steps. The investigator collected baseline data with the parents, and then the parents implemented baseline sessions with their children with autism before beginning the PECS training sessions.

\section{Parents}

Baseline sessions were conducted with each parent separately at a therapy room without their children. In this session, parents acted as the communication partner and physical prompter, and the investigator assumed the role of a child. A preferred item was held by the parent and the corresponding 
picture was placed on the table. Parents were told to allow access to the preferred item anytime if the investigators handed the picture card to the parent or reached for the item. If the investigator reached for the picture and handed the picture to the parent, the parent provided access to the item for $30 \mathrm{~s}$. If the investigator did not use the picture card or reached for the item without using PECS within $10 \mathrm{~s}$, the parent provided the item to the investigator to interact with the item for $30 \mathrm{~s}$. Each session consisted of 10 trials, and each session lasted about 10-12 minutes. No feedback was provided to parents during the baseline sessions. Three sessions were conducted daily, three times a week for 1-2 weeks. After reaching a stable data, the parents conducted baseline sessions with their children.

\section{Children}

The parent conducted baseline sessions with his or her child in the therapy room. The investigator used the BIE to provide instructions to the parent. The parent was given the communication book, a picture of a preferred item, and the corresponding item of the picture. The parent placed one picture on the cover of the communication book and presented the preferred item in front of the child corresponding to the picture and waited for the child to respond within $10 \mathrm{~s}$. If the child picked up the picture and gave it to his/her parent to get the preferred item, then the child was allowed access to the item for $30 \mathrm{~s}$. If there was no response or if the child just reached for the item without using the picture from the communication book, the parent allowed the child to access the preferred item for $30 \mathrm{~s}$ or if it was a food item, until it had been consumed. Each session lasted 10-12 minutes. After reaching a stable baseline data, the parents moved to the intervention phase to receiving PECS training.

\section{Intervention}

\section{Parent training}

The investigator conducted training with each parent prior to each phase of PECS training. The BST package included written and verbal instructions for each phase and how to conduct steps in each phase, modeling, practice, and feedback.

During the intervention session, the investigator and a graduate student modeled each Phase for one session to help parents understand the procedure. In Phase I, the parent handed the preferred item and waited for the graduate student (in the child's role) to respond within $10 \mathrm{~s}$. If the graduate student independently picked up a picture from the communication book and handed it to the parent, the parent praised the graduate student and immediately provided the item. However, if the graduate student did not independently pick up the picture, the parent physically prompted the student using full physical prompting to pick up the picture and hand it to the parent. The parent allowed the graduate student access to the preferred item for $30 \mathrm{~s}$. If the preferred item was food, the parent waited for the graduate student to consume it. Each session included 10 trials, and each session lasted 10-12 minutes. The parents practiced the procedure until they had reached $100 \%$ accuracy across two consecutive sessions. After each session, the investigator provided feedback to the parents as needed (e.g., wait for the child to initiate). When parents had mastered the criteria for Phase I, they implemented Phase I with their children.

The Phase II sessions were identical to the Phase I training sessions. However, the parents were taught to increase the distance between the graduate student and the communication book to pick up the picture and then hand it to the parent to receive the preferred item. After parents mastered Phase II, they implemented the Phase with their children.

In Phase IIIA, the parents were trained to practice picture discrimination and how to implement the error correction procedure. Parents implemented the error correction procedure when the graduate student did not pick up the correct picture card corresponding to the preferred item. During the training, the parent presented a highly-preferred item and a non-preferred item and two corresponding pictures of the items. When the graduate student picked up the correct picture of the preferred item, the parent immediately provided verbal praise (e.g., "Good Job! You chose the ball"), gave the graduate student the preferred item, and allowed access to the item for $30 \mathrm{~s}$. However, when the graduate student picked the picture of the non-preferred item, the parent gave the student the non-preferred item. When the student had a negative response (e.g., rejected the item, threw it away, or returned to the parent), the parent implemented a four-step error correction procedure including modeling, prompting, switching, and repeating. First, the parent modeled the correct response to the student. The parent then touched the correct picture, placed the picture next to the preferred item, presented it to the student, and named it. Second, the parent provided physical prompting by touching the student's hand, guiding the student to pick up the correct picture and hand the picture to the parent. Third, the parent paused for 2 to $3 \mathrm{~s}$ by asking the student to do an activity that was not related to the process to visually distract (e.g., touch your head) the student to ensure 
that the student did not simply repeat the process by imitation. However, the student was not allowed to access the item. Fourth, the parent rotated the two pictures on the coversheet in the communication book and began the next trial. When the parents had mastered the criteria by implementing the Phase IIIA, they implemented this Phase with their children.

In Phase IIIB, the same procedure as in Phase IIIA was conducted. However, in this Phase, the parent was trained to present two preferred items to the graduate student (in child's role) and provide two pictures corresponding to the items. Also, in this Phase, the parent provided the error correction procedure when the graduate student did not pick up the correct picture. When the student picked up a picture from the communication book and handed it to the parent, the parent said "Ok, take it" and waited for the student to reach for the item. If the student took the correct item that corresponded to the picture, the parent verbally praised the student, named the item, and immediately gave the item to the student. However, when the student took the item that was not corresponding to the picture, the parent blocked the response and immediately implemented the error correction procedure. When the parents mastered the criterion of implementing PECS with $100 \%$ within two consecutive sessions, they conducted this Phase with their children.

\section{Parents' implementation of PECS with their children}

Each parent implemented PECS Phases I to IIIB with his/her child. After a stable baseline, the parent was instructed to conduct the intervention sessions with his/her child in the therapy room with a one-way mirror. The intervention sessions were identical to the parent's training on PECS as previously described. During the intervention sessions, the investigator observed the sessions through a one-way mirror in the therapy room and provided immediate feedback through BIE. The children were required to master the criteria at $80 \%$ or above within each phase before moving to the next PECS phase.

\section{Bug-in-Ear (BIE)}

Throughout the parents' implementation of PECS with their children, including baseline sessions, parents were provided feedback using BIE. The investigator observed the parents and their child through one way mirror and provided immediate verbal feedback to the parents on implementing each Phase of PECS through BIE. The investigator used short phrases to provide feedback (e.g., "increase distance between you and the book," "wait for the child to initiate," "use error correction now").

The feedback through BIE was delivered immediately within $3 \mathrm{~s}$ after the target behavior occurred. The investigator collected data following each session by counting the number of feedback messages provided. No feedback was provided when parents implemented PECS correctly. From the point that parents did not receive feedback when they implemented PECS accurately, the BIE was gradually faded. Parents wore BIE for two consecutive sessions, and when they did not need any feedback from the investigator, the BIE was removed.

\section{Generalization}

Generalization sessions were conducted in each of the participant's homes to give the child the opportunity to request objects or activities using PECS Phase IIIB. Parents implemented generalization sessions and the procedure was identical to Phase IIIB. However, the parents did not use the BIE to receive feedback from the investigator.

\section{Follow up}

Two follow-up sessions were conducted at the participant's home one month after the generalization sessions. Follow-up sessions were conducted in the same manner as the generalization session.

\section{Interobserver Agreement (IOA)}

The investigator and a graduate student (independent observer) coded IOA data for at least $30 \%$ of all the sessions for the children's use of PECS when the parents implemented PECS sessions with their children. The IOA was assessed by comparing the number of total independent PECS exchanges to the number of independent PECS exchanges that were performed correctly. A point-to-point IOA procedure was used to calculate the percentage of IOA data. This entailed dividing the number of agreements by the sum of agreements plus disagreements to find the percentage at the end of each session. Overall, the mean IOA for Ray's responses was $98.4 \%$ (range 98-100\%) for all PECS Phases, and for Jack's responses, it was 99\% (range 97- 100\%) for all Phases.

\section{Treatment integrity}

The treatment integrity was collected twice for parents: during their implementation of PECS with the investigator (training period) and during their implementation of PECS with their children with ASD. For parent training, a minimum of $30 \%$ of the total sessions, including baseline and intervention was ob- 
served and evaluated by a trained independent observer using the PECS Implementer Skills Assessment [30] randomly distributed across sessions. The fidelity for Ray's mother during parents training was $100 \%$ during the baseline sessions, Phase I, and Phase II, and was 95\% during Phase III. The overall average for all Phases was 98\%. Jack's father had an integrity with a $100 \%$ for baseline and all phases I-III.

The integrity for parents' implementation of PECS with their children was collected for $30 \%$ of sessions. The results for Ray's mother was $100 \%$ for baseline, $98 \%$ for Phase I, $100 \%$ for Phase II, $94 \%$ for Phase IIIA, and $100 \%$ for Phase IIIB, generalization, and follow-up. The overall average of all Phases was 98.4\% (Figure 2). Jack's father's treatment integrity was $100 \%$ for baseline, $95 \%$ for Phase I, $100 \%$ for Phase II, $100 \%$ for Phase IIIA and IIIB, $100 \%$ for generalization and follow-up sessions. The overall average was $99 \%$ (Figure 3 ).

\section{Social validity}

Social validity of the intervention was assessed using the
Treatment Acceptability Rating Form-Revised (TARF-R) [31]. The form was distributed to the parents to assess the extent to which they found the sessions acceptable to the goals, procedures, and outcomes of the intervention. This 12-item questionnaire used a 6-point Likert rating scale. The results revealed that both parents were satisfied with the goals, procedure, and outcome of the study. With regards to the question concerning the parents' understanding of the treatment package, both parents indicated a very good understanding of the treatment and found it very acceptable, Finally, when parents were asked how well they perceived the applicability of the treatment for other settings, both parents answered very well.

\section{RESULTS}

\section{Parents' acquisition of PECS using BST}

\section{Ray's mother}

The top panel of Figure 1 shows data for Ray's mother. During baseline, she did not request any items using PECS icons indi-

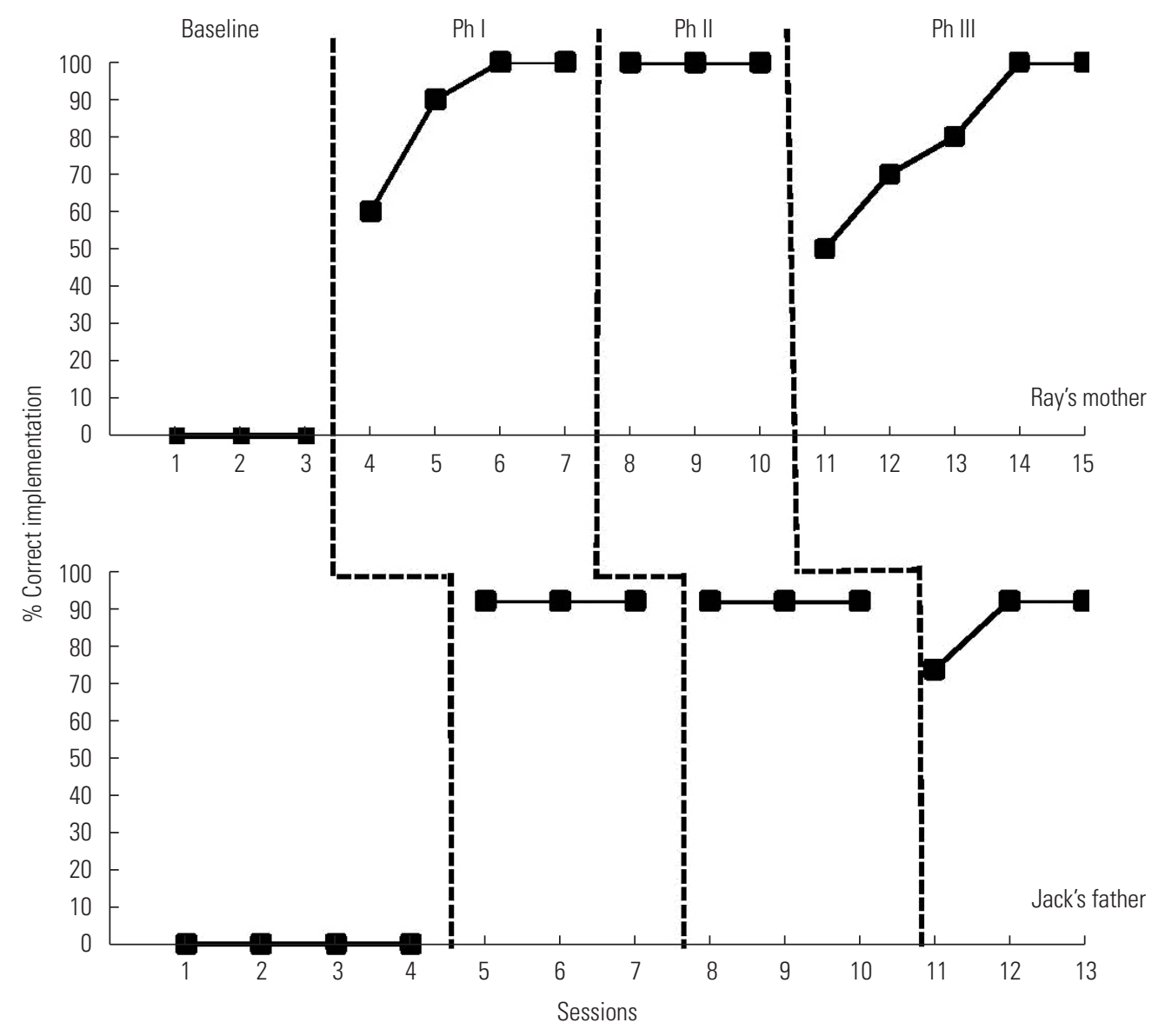

Figure 1. Percentage of accurate implementing PECS of parents. Ph, PECS phase. 


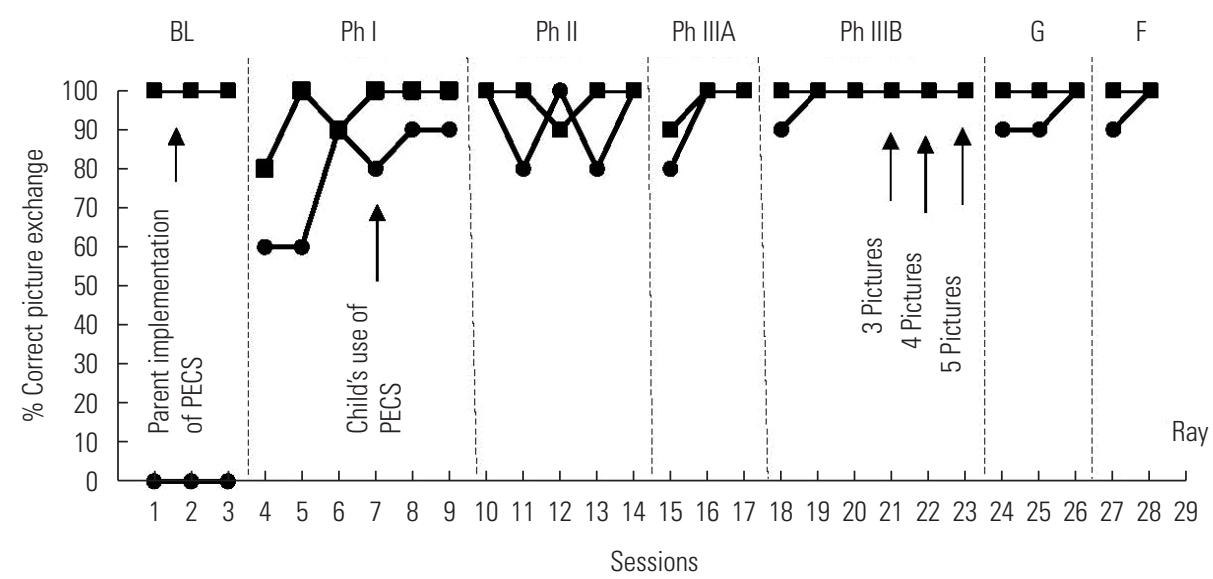

Figure 2. Percentage of independent Picture Exchange during baseline, PECS Phases, and follow up for Ray. BL, baseline; Ph, PECS phase; G, generalization; F, follow-up.

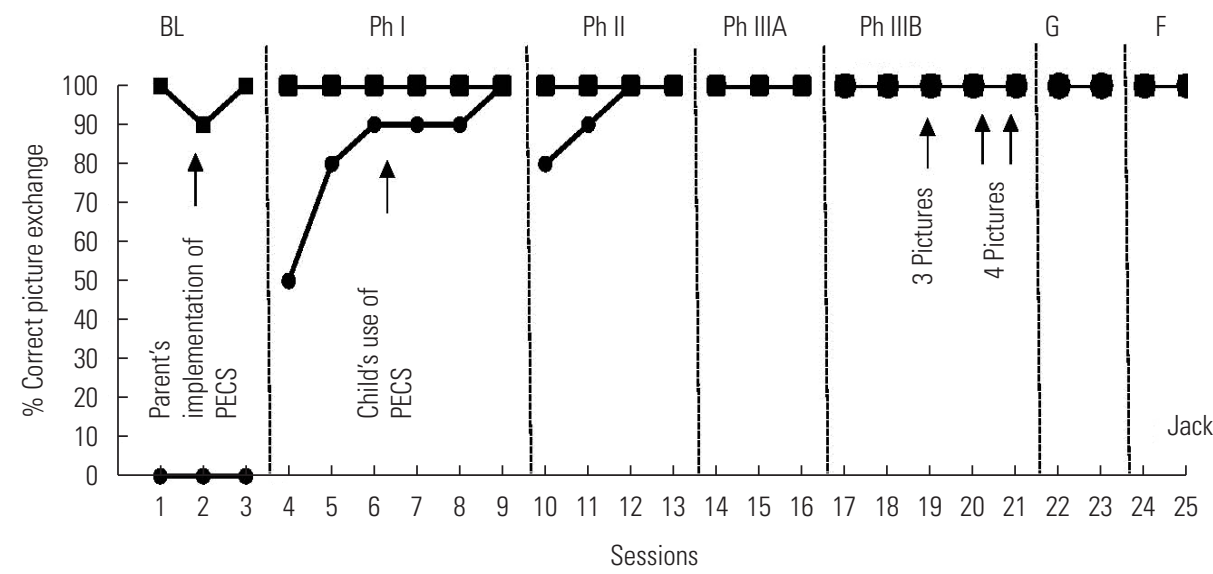

Figure 3. Percentage of independent Picture Exchange during baseline, PECS Phases, and follow up for Jack. BL, baseline; Ph, PECS phase; G, generalization; F, follow-up.

cating stable data. However, when the training began, her correct implementation of PECS had a moderate to high level and a gradually increasing trend from $60-100 \%$ (average $=88 \%$ ) at the end of Phase I. Phase II training included three sessions where she reached $100 \%$ in all the training sessions with a stable data path. Phase III training included an increasing trend from $50-100 \%$ (average $=80 \%$ ), and she mastered the criterion after five training sessions.

\section{Jack's father}

The bottom panel of Figure 1 indicates data for Jack's father. In baseline, he did not implement PECS correctly and had stable data. In Phase I, he participated in three sessions and achieved the criterion of $100 \%$ with an immediate change in level and trend. Similarly in Phase II, he met the mastery criteria with $100 \%$ accuracy with a stable data path with no change in level or trend. In Phase III, he met the criteria in the second session with an increasing trend from $80-100 \%$ (average $=93 \%$ ).

\section{Requesting skills of children with ASD using PECS Ray}

Results in Figure 2 show that Ray's progress in requesting items. During baseline sessions, Ray did not request preferred items using PECS with a stable data path. When his mother implemented PECS training sessions, Ray's correct responses using PECS increased from $60 \%$ to $90 \%$ (average $=78 \%$ ) by the end of Phase I with an increasing trend with some variability. During Phase II, Ray showed a variable and high-level data and achieved $100 \%$ of correct responses using PECS icons. At the end of this Phase, Ray could travel to PECS (6-foot distance) with an average of $92 \%$ accuracy. Results from Phase 
IIIA show that Ray met the criterion with a high level with an increasing trend from $80 \%$ to $100 \%$ (average $=93 \%$ ) with low variability. During Phase IIIB, Ray was required to discriminate among an array of pictures of preferred items and gradually increased the number of preferred items and pictures that corresponding to the presented items. For this Phase, the data showed that Ray had a stable pattern with a high level and $100 \%$ of correct responses. The number of pictures was gradually increased to five picture cards, and Ray acquired the skills with $100 \%$ correct exchanges with an average of $98 \%$.

Three generalization sessions were conducted at Ray's home by his mother. Ray's generalization data across settings indicated an increasing trend with a range of $90-100 \%$ (average $=93 \%$ ). After one month had elapsed, two follow-up sessions were conducted at Ray's home with procedures identical to the generalization sessions. Ray demonstrated a high level of correct responses with using PECS. The data showed that Ray's correct response with a range of 90-100\% (average $=95 \%$ ), showing an increasing trend.

\section{Jack}

Figure 3 displays the percent of independent picture exchanges by Jack. During the baseline sessions, Jack did not perform any requesting skill correctly showing a stable baseline. Data from Phase I displays an increasing trend from 50\% to $100 \%$ (average $=83 \%$ ) of independent requesting responses. Jack mastered Phase II in four sessions with a range of 80$100 \%$ (average $=92 \%$ ) indicating an increasing trend with a high level of correct responses. Jack mastered Phase IIIA in three sessions with $100 \%$ correct responses with a stable data path with no trend or level change. Jack also mastered Phase IIIB with $100 \%$ accuracy with no change in level or trend during all sessions with a gradual increase in the number of picture cards up to four pictures.

Jack's father conducted two generalization sessions at their home. Jack's data for the generalization sessions across settings demonstrated a stable data with $100 \%$ accuracy. After one month had elapsed, two follow-up sessions were conducted at Jack's home where the procedure was identical to the generalization sessions. Jack demonstrated $100 \%$ correct responses using PECS with a stable data.

\section{BIE and feedback provided to parents}

During the sessions, the investigator provided feedback to the parents through BIE when they incorrectly implemented or missed steps of PECS phases. In addition, the investigator tracked the BIE feedback message frequency provided to parents. In Phase I, Ray's mother received a total of 10 feedback messages though BIE while in Phase II, she received three messages through the BIE. In Phase IIIA, she received one feedback message. Jack's father implemented Jack's father received 11 feedback messages in Phase I, 1 in Phase II, and did not need any feedback in Phase IIIA. The BIE was discontinued during Phase IIIB for both parents.

\section{DISCUSSION}

This study examined the effects of using a BST package during parents' training in PECS implementation with their children with autism to develop requesting skills. Results show that both parents successfully learned the training procedures of each phase of PECS and taught their children to improve requesting skills with high procedural integrity. Although there were some variabilities in the length of time required for each child to master the criterion, both children with autism acquired independent picture exchanges when parents implemented the PECS procedure. In addition, both children generalized their communication skills by using PECS at their home and maintained the acquired skills for at least one month post training. Furthermore, parents required less feedback through BIE during PECS implementation. However, we did not control or experimentally analyze BIE feedback during intervention sessions limiting the conclusions. Additionally, results of social validity indicate that both parents were satisfied with the goals, treatment package, and outcomes of PECS.

The results indicated that both parents taught their children PECS with high levels of integrity across phases. The findings suggest that when parents receive appropriate training and feedback, they can train their children to use PECS to independently request desired items or activities. The current study extends existing research on PECS by teaching parents as the primary PECS trainers to implement the strategy with their children [12-16]. This study also provides some preliminary evidence of using BIE feedback with parents to implement PECS with their children. Since, BIE effect was not experimentally demonstrated, future researchers should test the efficacy of BIE in PECS training studies [21,22].

The finding of this study replicated those obtained from previous studies that reported most of the children acquired PECS skills effectively [17,32]. The parents' implementation of PECS training had a positive influence on their children in 
terms of the percentage of independent picture exchanges as well as the number of steps that they independently completed.

Several possible reasons may have contributed to the positive outcomes in this study. First, PECS is a systematic intervention that includes clear and specific procedural guidelines. Once a person understands the procedure and follows the steps to implement PECS, it is possible to gain high procedural integrity. Second, the training procedure included a BST package to teach the parents how to implement PECS. This package consisted of different components that included written guidelines, verbal explanations, video clips, modeling, practice, and immediate feedback consistent with best practice as indicated in parent/teacher training literature [33-35]. Third, both parents in this study had a high level of education and voluntarily participated in the study. Thus, their educational level may have had a positive impact on their understanding of the PECS and they were motivated to learn the skills.

In addition to the parents training, other factors may have facilitated the children's acquisition of PECS. For example, individuals with autism are visual learners [36], and PECS provides the visual stimuli including colored photographs of preferred items that match corresponding objects. In addition, the use of highly preferred items including edible items and toys identified through preference assessments may have motivated children with autism to request preferred items through exchange of pictures.

In this study, parents implemented PECS with high integrity. However, parents required the highest number of feedback through BIE during Phase I of PECS because of the problem behaviors that were displayed by their children with autism. Thus, feedback through BIE may have improved parents' implementation of the PECS Phase I and contributed to the reduction of problem behaviors in subsequent stages. For example, Phase III included several steps and the error correction procedure but parents only needed minimal or no feedback and implemented the phase without any assistance.

\section{Limitations and future recommendations}

Although the findings of this study demonstrated positive outcomes, some limitations were found that need to be addressed in future research. First, the parents received training only in Phase I, II, III; all six phases of PECS were not included due to the restricted time frame for the study. Therefore, future research needs to extend the parents' training needs to include all six phases of PECS. Second, we did not systematically evaluate the impact of BIE. Thus, the results should be considered preliminary and future researchers need to use a rigorous experimental design to evaluate the impact of BIE when training parents to implement PECS. Third, this study involved only two parents and two children with autism which provided limitations in demonstrating the functional relationship across participants using a multiple baseline design. Researchers recommend that at least three or replications are needed in single-case experimental designs [27]. Future research needs to be conducted using three or more participants to demonstrate functional relations.

\section{REFERENCES}

1. Sigafoos J, Drasgow E, Reichle J, O'Reilly M, Tait K. Tutorial: teaching communicative rejecting to children with severe with severe disabilities. Amer J Spe-Lang Path. 2004;13:31-42.

2. Keen D, Sigafoos J, Woodyatt G. Replacing prelinguistic behaviors with functional communication. J Auti Dev Dis.2001;31:385-398.

3. Lovaas OI. Behavioral treatment and normal educational and intellectual functioning in young autistic children. J Cons Clin Psy. 1987;55:3-9.

4. Sundberg ML, Michael J. The benefits of Skinner's analysis of verbal behavior for children with autism. Beh Modif. 2001;25:698724.

5. McFadden B, Kamps D, Heitzman-Powell L. Social communication effects of peer-mediated recess intervention for children with autism. Res Auti Spec Dis. 2014;8:1699-1712.

6. Wret BY, Neisworth JT. Effects of video self-modeling on spontaneous requesting in children with autism. J Pos Beh Inter. 2003;5: 30-34.

7. Beukelman DR, Mirenda P. Augmentative alternative communication: supporting children and adults with complex communication needs. Baltimore, MD: Paul Brookes; 2005.

8. Bondy A, Frost L. The picture exchange communication system. Foc Auti Beh. 1994;9:1-19.

9. Hart SL, Banda DR. Picture exchange communication system with individuals with developmental disabilities. Rem Spec Edu. 2009;31:476-488.

10. Bondy A, Frost L. The picture exchange communication system. Beh Mod. 2001;25:725-744.

11. Alsayedhassan B, Banda D, Griffin-Shirley N. A review of picture exchange communication interventions implemented by parents and practitioners. Chil Fam Beh Ther. 2016;38:191-208.

12. Carson L, Moosa T, Theurer J, Cardy JO. The collateral effects of PECS training on speech development in children with autism. Can J Spe-Lang Path Aud. 2012;36:182-195.

13. Chaabane DB, Alber-Morgan SR, DeBar RM. The effects of parentimplemented PECS training on improvisation of mands by children with autism. J Appl Beh Anal. 2009;42:671-677. 
14. Greenberg A, Tomaino M, Charlop M. Assessing generalization of the picture exchange communication system in children with autism. J Dev Phy Dis. 2012;24:539-558.

15. Park JH, Alber-Morgan SR, Cannella-Malone H. Effects of motherimplemented picture exchange communication system (PECS) training on independent communicative behaviors of young children with autism spectrum disorders. Top Ear Chil Spec Edu. 2011;31:37-47.

16. Stiebel D. Promoting augmentative communication during daily routines: a parent problem-solving intervention. Jour Pos Beh Inter. 1999;1:159-169.

17. Barnes CS, Dunning JL, Rehfeldt RA. An evaluation of strategies for training staff to implement the picture exchange communication system. Res Aut Spec Dis. 2011;5:1574-1583.

18. Charlop M, Malmberg D, Berquist K. An application of the picture exchange communication system (PECS) with children with autism and a visually impaired therapist. J Dev Phy Dis. 2008;20:509525.

19. Magiati I, Howlin P. A pilot evaluation study of the Picture Exchange Communication System (PECS) for children with autistic spectrum disorders. Autism: Inter J Res Prac. 2003;7:297-320.

20. Scheeler MC, Ruhl KL, McAfee JK. Providing performance feedback to teachers: a review. Teach Edu Spec Edu. 2004;27:396-407.

21. Scheeler MC, McAfee JK, Ruhl KL, Lee DL. Effects of corrective feedback delivered via wireless technology on preservice teacher performance and student behavior. Teac Edu Spec Edu. 2006;29: 12-25.

22. Scheeler MC, Lee DL. Using technology to deliver immediate corrective feedback to preservice teachers. J Beh Edu. 2002;11: 231241.

23. Lord C, Rutter M, DiLavore P, Risi S, Gotham K, Bishop S. Autism Diagnostic Observation Schedule-2nd Edition (ADOS-2). Los Angeles, CA: Western Psychological Corporation; 2012.

24. Sparrow S, Cicchetti DV, Balla DA. Vineland-II Adaptive Behavior Scales- Second Edition (Vineland-II). Minneapolis, MN: Pearson Assessments; 2005.
25. Roid GH. Stanford-Binet Intelligence Scales, Fifth Edition. Itasca, IL: Riverside Publishing; 2003.

26. Gilliam J. GARS-2: Gilliam Autism Rating Scale-second edition. Austin, TX: PRO-ED; 2006.

27. Cooper JO, Heron TE, Heward WL. Applied behavior analysis (2nd ed.). Upper Saddle River, NJ: Pearson Education, Inc; 2007.

28. Ganz JB, Simpson RL. Effects on communicative requesting and speech development of the picture exchange communication system in children with characteristics of autism. J Auti Dev Dis. 2004;34:395-409.

29. DeLeon IG, Iwata BA, Roscoe EM. Evaluation of multiple-stimulus presentation format for assessing reinforcer preferences. J App Beh Anal. 1997;29:519-533.

30. Frost LA, Bondy AS. The picture exchange communication system training manual (2nd edition). Newark, DE: Pyramid Educational Products; 2002.

31. Reimers TM, Wacker DP, Cooper LJ, De Raad AO. Acceptability of behavioral treatments for children. School Psychology Review. 1992;21:628-643.

32. Lerna A, Esposito D, Conson M, Russo L, Massagli A. Social-communicative effects of the picture exchange communication system (PECS) in autism spectrum disorders. Inter J Lang Com Dis. 2012;47:609-617.

33. Homlitas C, Rosales R, Candel L. A further evaluation of behavior skills training for implementation of the picture exchange communication system. J App Beh Anal. 2014;47:1-6.

34. Miles NI, Wilder DA. Effects of behavioral skills training on caregiver implementation of guided compliance. J App Beh Anal. 2009;42:405-410.

35. Rosales R, Stone K, Rehfeldt RA. The effects of behavioral skills training on implementation of the picture exchange communication system. J App Beh Anal. 2009;42:541-549.

36. Quill KA. Teaching children with autism: Strategies to enhance communication and socialization. Albany, NY: Delmar Publishers; 1995. 